\title{
SURVEILLANCE OF FATAL MOTOR VEHICLE ACCIDENTS IN MICHIGAN, INVOLVING YOUNG DRIVERS, UTILIZING TIME-SERIES ANALYSIS OF POLICE RECORDS*
}

\author{
Stanley H. Schuman†, M. Anthony Schork + and Sovgsee Srivannaboons \\ University of Michigan
}

(Received 5 August 1969; in revised form 10 December 1969 )

\section{PART I. INTRODLCTION}

IS THERE ANY ASPECT of traffic safety more urgent than the problem of dangerous young drivers? Although they may seem to be unduly criticized, the available facts establish drivers under 25 years of age as a group with extraordinarily high risk.

Why are young drivers over-represented year after year in fatal accidents? Why is their death rate consistently higher than that of drivers of older ages? Why are young drivers over-represented in single car, off-the-road crashes? These questions are of more than academic interest. Answers to them would seem to be essential to any efforts at primary or pre-crash prevention of fatal motor vehicle accidents.

Many approaches to resolving these questions are being employed where appropriate data are being collected. In this report the State of Michigan provides the data for applying several methods of analysis which have been useful in epidemiologic research and public health practice. In particular, the use of the time series is presented as a practical and reasonable way of following fatal accident data in an ongoing fashion.

\section{Dimensions of the problem}

The extent of the young driver problem in Michigan is not small. In fact, when young drivers on Michigan highways are tabulated, one notes two facts: (1) about one tenth of the licensed driving population is age 19 and younger, and (2) last year (1968) over 85.000 new drivers, aged 16 years, entered the driving population. That number will most likely increase with each year.

Are there more young drivers in Michigan than other states? Statistics (Table 1A) indicate that there is no heavily populated state in the U.S. that has a higher percentage of young drivers than Michigan. We have selected the seven most populous states, which represent 48 percent of the total of U.S. population. One finds that in Michigan, the number of drivers licensed who are age 19 and younger comprises over 11 per cent of the total driving population!

A possible reason for this heavy proportion of young drivers in Michigan is suggested in Table 1B, wherein the age requirement for learner's permit, operator's license and the percentage of schools offering public-supported driver education are shown. Michigan has a young age (16) for learner's permit and all of the schools offer public-supported

\footnotetext{
* This study is supported by the University of Michigan Highway Safety Research Institute (R. L. Hess, Director) with the assistanec of The Michigan Department of State Police (F. E. Davids. Director, Syt. Dorald Calcatera, Traffic Analyst).

† Associate Professor. Department of Epidemiology, School of Public Health.

+ Associate Professor. Department of Biostatistics. School of Public Health.

Sesearch Assistant. Department of Epidemiology and Highway Safety Research Institute.
} 


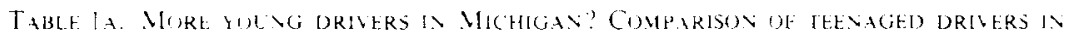
MICHIGIS WTH OTHER STATES ISELECTION OF SEVEX WOST POPLLOCS STATES. COMPRISING

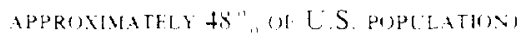

\begin{tabular}{|c|c|c|c|c|}
\hline \multirow{2}{*}{ Scalte } & \multirow{2}{*}{$\begin{array}{c}\text { Approximate } \\
\text { ". of } \\
\text { Pupulition } \\
\text { of Cs.* }\end{array}$} & \multicolumn{3}{|c|}{ " of total licensed driving population. 190?" } \\
\hline & & $\begin{array}{l}\text { tge } 17 \\
\text { and vounger }\end{array}$ & $A \underline{y} \cdot 18-14$ & $\begin{array}{l}A \text { ov } 19 \\
\text { and younger }\end{array}$ \\
\hline Michigan & $+\cdot 36$ & $+4+$ & 6.68 & 11.12 \\
\hline Texal & 5.34 & $5+2$ & $5+7$ & $10 \cdot 59$ \\
\hline Ponnyltanial & $6: 1$ & 3.39 & $50 ?$ & $8+2$ \\
\hline Illanuis & $5 \cdot 62$ & 3.53 & 487 & $s+1$ \\
\hline Ohin & $5+1$ & 347 & 4.91 & $8 \cdot 34$ \\
\hline Caliturntal & $8 \cdot 76$ & $3 \cdot 16$ & 398 & $7 \cdot 14$ \\
\hline Vew Jersey & 3.35 & 2.25 & +86 & $7 \cdot 11$ \\
\hline lew roul & ). 36 & $1.1^{7}$ & 401 & $5+4$ \\
\hline
\end{tabular}

* The lyoy World Almanac and Book of Fitets. Luman H. Long. Editor, New York. iv. Y. 10017. Page 59311960 census).

t lis. Department of Tamportation. Burba of Public Roads. Table DL 21. 1967.

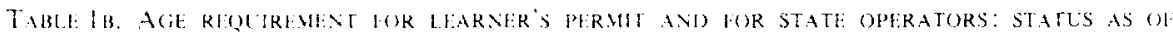

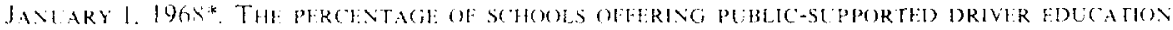

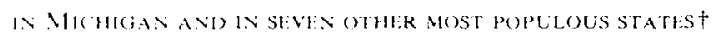

\begin{tabular}{|c|c|c|c|c|}
\hline \multirow[b]{2}{*}{ Statc } & \multirow[b]{2}{*}{$\begin{array}{l}\text { Loarnors permit } \\
\text { minimum dget+ }\end{array}$} & \multicolumn{2}{|c|}{$\begin{array}{c}\text { Operator's license } \\
\text { (unlimited operation) }\end{array}$} & \multirow{2}{*}{$\begin{array}{l}\text { Percentage } \\
\text { of Suholi } \\
\text { offering } \\
\text { public-supported } \\
\text { driver education }\end{array}$} \\
\hline & & $\begin{array}{l}\text { No special } \\
\text { provisions }\end{array}$ & $\begin{array}{l}\text { Special provision } \\
\text { for minorss }\end{array}$ & \\
\hline Michigan & 16 & is & 16 & 100 \\
\hline Texits & 1518 & 18 & 15 & 59 \\
\hline Pennsylvania & 16 & 18 & 17 & 99 \\
\hline lilinois & 1518 & 21 & 18 & 100 \\
\hline Ohio & 16 & 21 & 16 & 89 \\
\hline Calilorna & $15 \%$ & 18 & 16 & 76 \\
\hline New Jersey & 17 & 17 & & $x \rightarrow$ \\
\hline New York & 16 & 18 & 17 & 94 \\
\hline
\end{tabular}

* C.S. Department of Transportacion. Federal Highway Adninistration. Washington D.C. 20591. Taltic DL 101. January 1968.

+2ist Annual Driver Education Achievement Program 1967-1968 School Year. From /nvarance

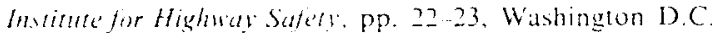

+ Where more than one age is shown for a Stats, the lower age is qualifed by certain reserictions.

Signature of parent or guardian is mandatory betore sisuance of license.

driver education which potentially pours many high school age drivers into the licensed category. Care must be used in applying the young age-high per cent of schools with driver education hypothesis as Texas has only 58 percent of its schools with driver education but it is second to Michigan in per cent of young drivers. New York State has a distinctly lower proportion of teenaged licensed drivers than the other states which must reflect. in part. the use of public rather than private transportation in the most hearily populated city in the State. New York City.

'Woodwarding' in the Motor City.

Among the reasons for Michigan being a 'young driving state' is the inevitable effect 
of the youngsters growing up in an area with an automobile-dominated economy and in a culture increasingly influenced by the car. A recent series of articles in The Detroit Fre'e Press describes some of the current automotive features of the teenage subculture in the large city. These characteristics may prevail with slight variation in urban and suburban centers in many other states. The articles by Mary Ann Weston were published on June 4. 5. 6. 1969, entitled, 'The Strip: Kids and Cars Own It': 'North Woodward: Where Kids Reign in Racing Cars": 'The Strip's Big Todd: Fanatic With Hot Cars'; 'Big Lure of N. Woodward: It's Where the Girls Are'; and 'The Street-Racing Capital of the World'. The following excerpt accompanied by colored night photographs of zig-zag light patterns suggests the theme of the articles.

-The Woodward Strip stretches wide and straght from Ten Mile Road to Square Late. south of Pontial --.. cight lanes and 11.2 miles of neon-studded. headlight-streaked teenage playground.

It's "The Place" where teens test their surging modified machines against the best that Detroit can come up with. where girls come to meet boys and vice versa, where drive-ins monuments to teenage culcure and appetites-provide pit stops for the young drivers who cruise up and down. around and around. in the crazy game the kids call "Woodwarding"

\section{PART II. THE TIME SERIES APPROACH}

\section{Source document}

Figures $1 \mathrm{~A}$ and $1 \mathrm{~B}$ form the basic document filled out by an officer in the State of Michigan at the scene of an accident. Any limitation in his reporting or erroneous observations, omissions, or defects in the form are perpetuated from this document to the compiled statistics. The limitations of the data must be kept in mind as we ask statistical questions: thus, age, sex, residence of drivers involved (Section F. Fig. 1A) are usually accurate; more subjective questions such as apparent physical condition of driver (Section P. Fig. I B) or vehicle condition (Section S. Fig. IB) are unlikely to yield consistent or reliable information on a statewide basis. One may note for example, in Table $2 \mathrm{~A}$, that age of driver involved is missing in 1-2 per cent of FMVA.

\section{Developing hase line graphs}

The number of fatal motor vehicle accidents (FMVA) in Michigan by 7 day periods as the 5 year, 3 week moving mean* for the years 1961-1965 are plotted in Fig. 2. This mean is derived from the available records counting each accident involving a fatality as a single event whether one died or many persons were killed, and whether the person killed was a pedestrian, bicyclist, passenger or driver. The date of the accident is plotted, regardless of date of death.

Subsequent tabulations are focused on the age of the driver involved rather than on age of person killed. This characteristic was chosen because it is noted routinely and uniformly on the accident form and is subject to very little bias. One is not counting only those who are judged at fault by the reporting officer who assigns the labels. "car no. 1' and 'car no. 2' etc. in a multiple car crash (Section F. Fig. $1 \mathrm{~A}$ ). Ideally, one would like to separate these drivers who are most responsible for the accidents from the least responsible or innocent drivers, but such decisions are difficult to make and are not available in objective or

\footnotetext{
* Five year. three week moving mean: $\left[x_{t}=\left(\sum_{i=1}^{5} \sum_{t=1}^{-1} x_{i}\right): 15\right]$ where $x$ is the number of accidents occurring in the $j$ th week of the $i$ th year and $t$ is the week in the year of the mean. Any 5 year average might be weighted for the most recent year's experience in order wacilitate the study of trend effects. Such a weighting always involves certain assumptions which may nevertheless be quite useful.
} 
STATE OF MICHIGAN

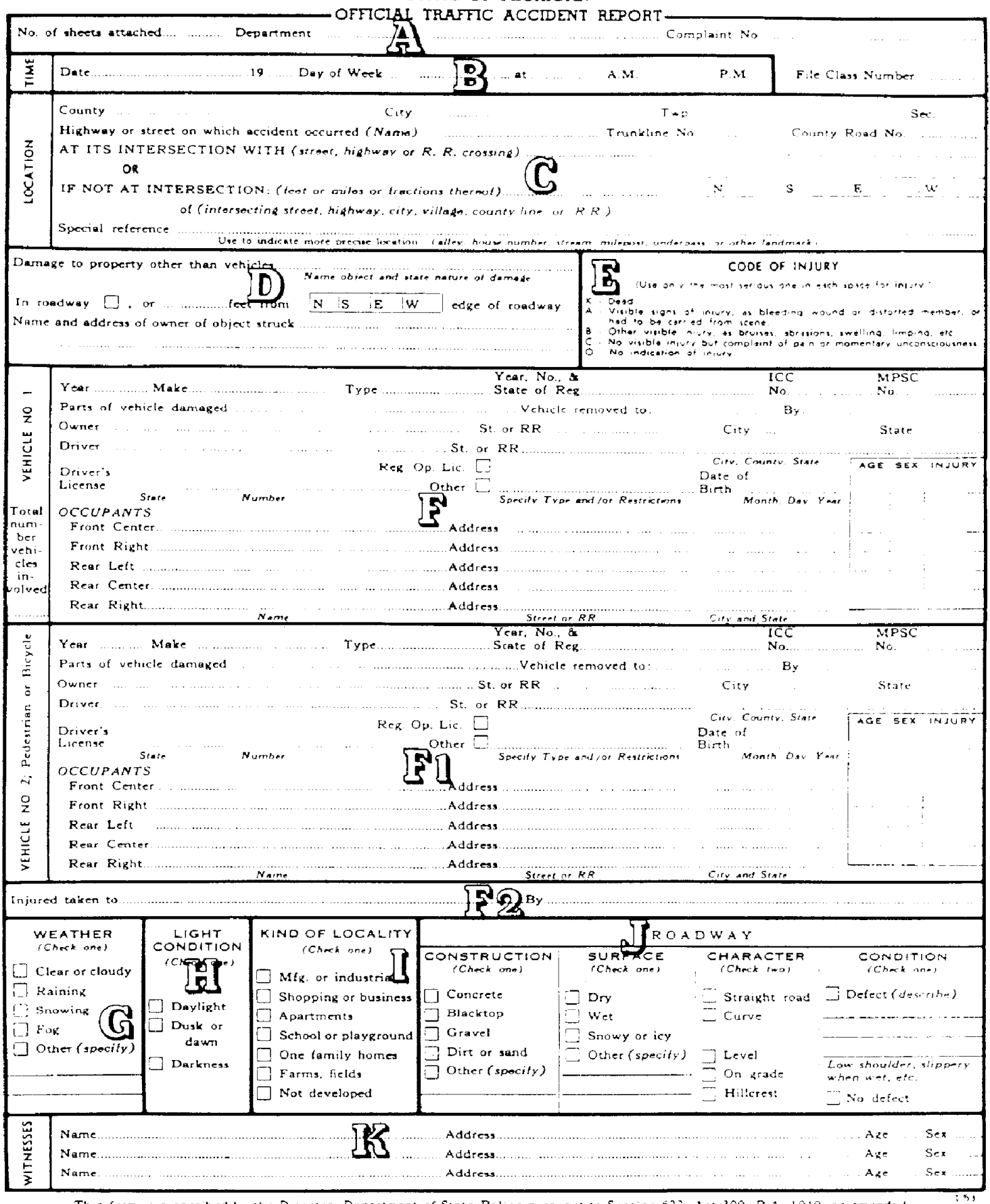

This form is prescribed by the Direcior. Department of State Police pursuant :o Section 622, Ace 300. P. A. 1049, as amendet 
ALL APPLICABLE SCHEDULES MUST BE CHECKED. OFFICERS CONSIDERED OPINION SHOULO BE CIVEN IF FACTS ARE NOT OBTAINABLE

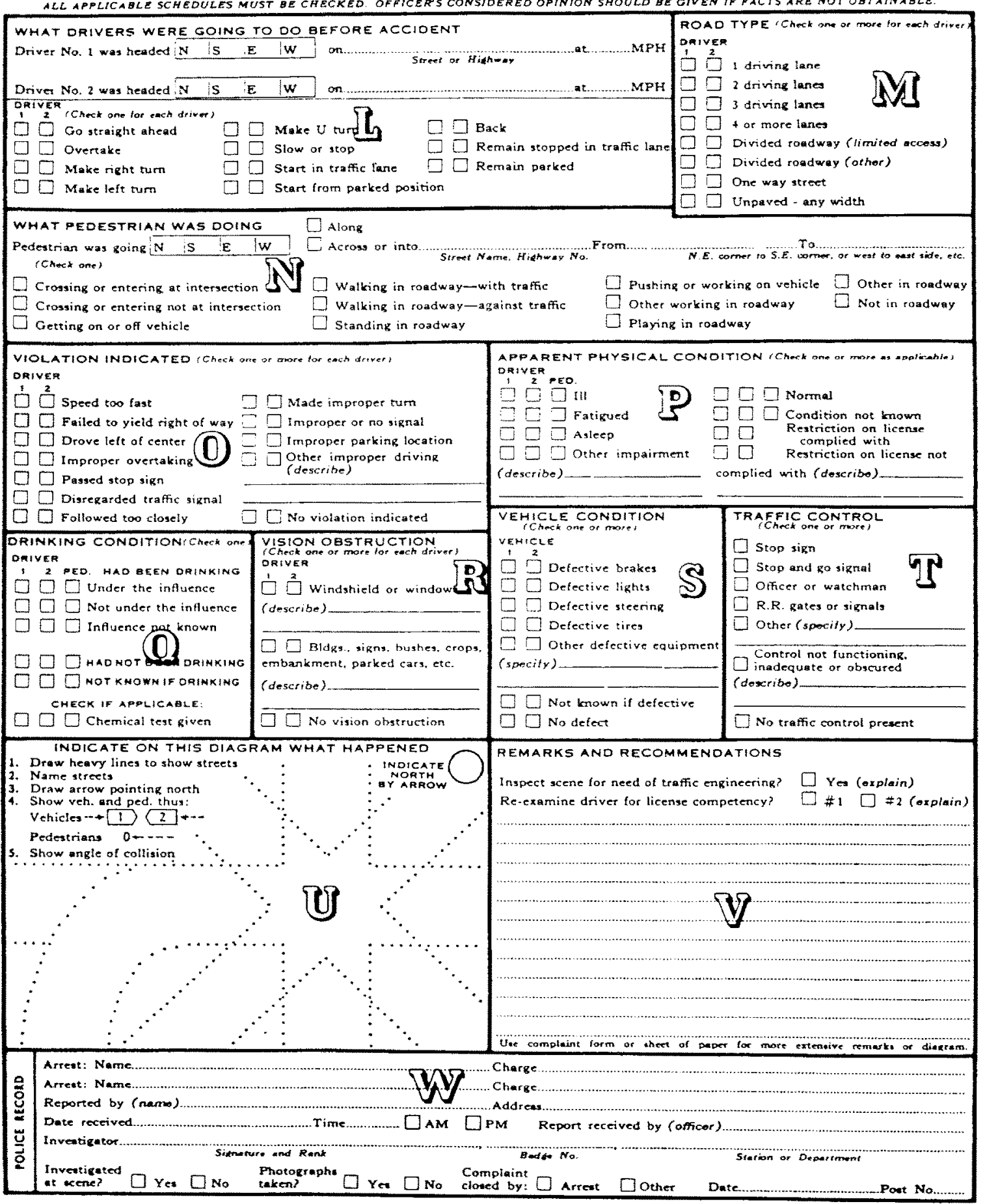

Fig. 1A, B. Form UD-10C. 


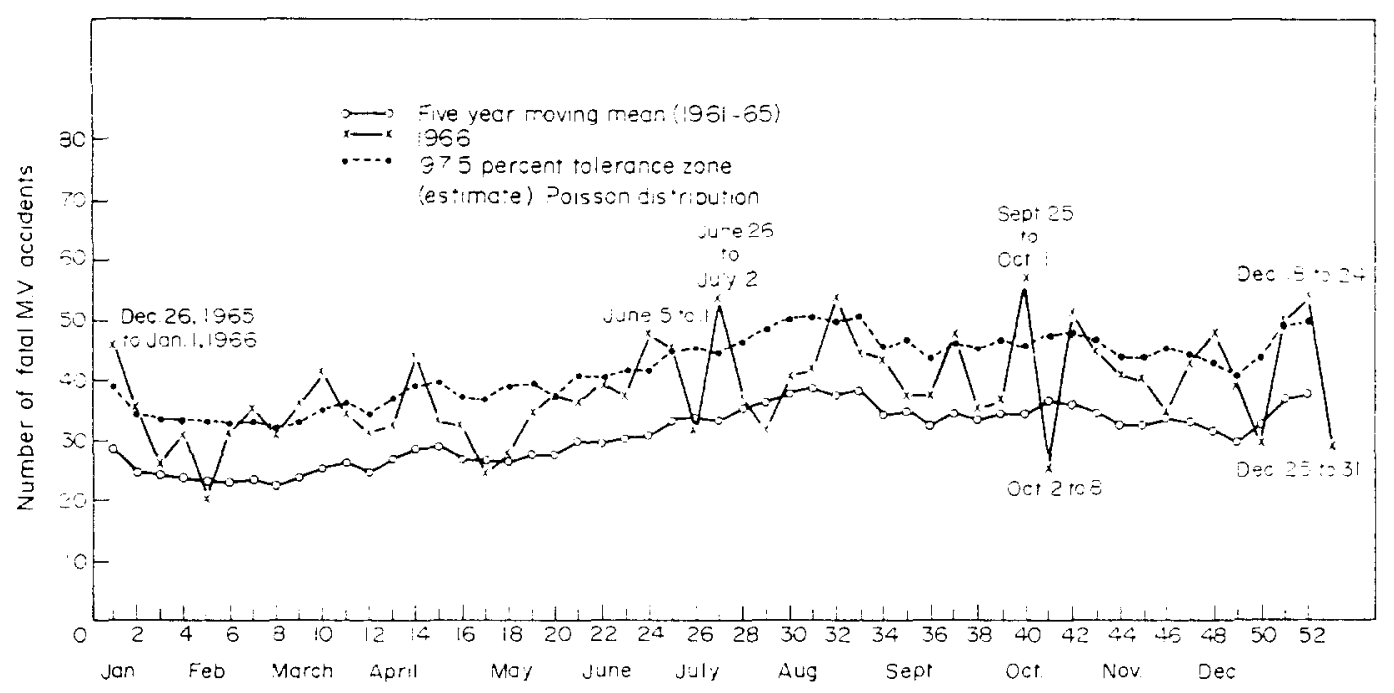

Fic. 2. Vumber of latal motor vehicle accidents in Michigan. Plotted by seven-day periods.

systematic form. Furthermore, from the overall traffic safety viewpoint, the person involved in any accident may be guilty of one or more errors in the skills of defensive driving. Whether the driver's error is due to temporary inattention or to deliberate and aggressive risk-taking, the end results are the same. An example is a multiple car crash in 1968 in the Bay City area in which 28 cars collided resulting in a single fatality. All 28 drivers were involved and were guilty of speeding and following too closely for the prevailing conditions. Incidentally, 12 of the 28 involved drivers were under age 25 . Imperfect as number and age of drivers involved may be as an index of measure, it should provide some interesting clues to driver performance in FMVA in Michigan during recent years.

What do the data in Fig. 2 indicate? There is a fairly stable curve with gentle undulation rising to a peak around August and staying high for September and October, providing a secondary peak in the holiday season from mid-December to mid-January. An effort was made to plot a tolerance zone above which one would suspect there was an unusually high frequency of fatal accidents, and this is indicated on our graph as an estimated Poisson 97.5 per cent tolerance zone covering about the lower 90 per cent of the population $(\bar{x}+2 \sqrt{\bar{x}})$. Then, primarily for demonstration purposes, the 1966 data on fatal accidents In Michigan were plotted as \%-day totals against the provided background of the 5 year moving mean and tolerance zone. Note that short term peaks appear and that some of these are followed by low points, and these peaks probably represent chance variation rather than sustained increases over the expected number of the events. Specifically, one could suspect that in 1966 the eighth, ninth and tenth weeks were consistently at the upper limits of the tolerance zone. On the other hand, the sharp rise for week number forty is not sustained, but drops the following week by almost the same amount ( $36 \pm 15$ ). One could conclude that for 1966 there were no sustained peaks of fatal accidents that would represent 2 ur 3 week elevations above the expected tolerance zone other than the modest March series. This emphasizes what has been brought out by others, that the dramatic holiday excesses may represent 1 week peaks, while the preceding and succeeding periods show normal or below normal frequencies. 


\section{Rate's of insolved drivers}

The data in Fig. 3 (A, B and C) were developed after Fig. 2. because we felt that rates of fatal motor vehicle accidents might provide more meaningful comparisons than the number of such accidents. particularly since we are concerned about young drivers. Thus a simple increase in the number of young drivers might occur to the 'Baby Boom' or to the increased availability of cars. For age-specific numerators, age-specific denominators were required. The best available intormation in the state provided the number of licensed drivers by age group for the specified years. These graphs were plotted as a prototype for the selected younger age groups: later, similar graphs will be plotted for middle age and older age groups. Beginning with Fig. 3A, let us compare the 3 year mean of the 3 week moving mean for the years 1964-65-66, showing FMVA as the rates per 1,000,000 licensed drivers for the age group 20-24 and for the age group 18-19.

It should be noted that for these younger drivers. only the 3 most recent years of Michigan experience were selected (1964-65-66) to compare with the incoming data of 1967 . The use of the 3 year mean results in a less stable curve than a 5 year mean, but may come closer to reflecting the most recent pattern of young driving behavior.

Fig. $3 \mathrm{~A}$ indicates that for the recent years of study in Michigan a more stable curve of FMVA involvement for the age group 20-24 is found than for the ages 18-19. There are peaks for summer and fall, which are not unexpected as they coincide with the peaks for all age groups in Fig. 2. Of distinct interest is the fact that the $18-19$ year old drivers were more involved in FMVA by season than the slightly older group. The teenaged motorists are definitely under-represented (as a rate) in FMVA in the first 15-20 weeks of the year, then their numbers peak sharply in July (week 25) and September (weeks 32, 33 and 34). The dip for teenagers during week 40 is short-lived as their rates exceed the $20-24$ year old rates for the rest of the year.

\section{Baseline compared to current vear}

Understanding the recent 3 year pattern, one can move to Fig. 3 B for comparisons with the most recent year, 1967. Let us focus first on those drivers, aged 20-24. One can see that

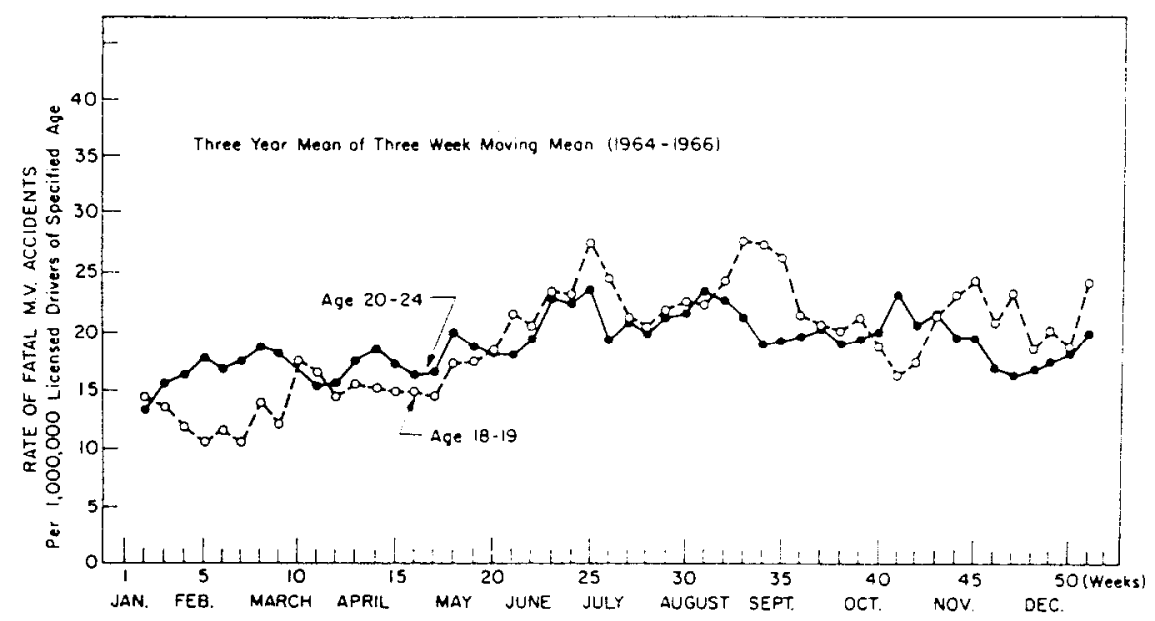

FIG. 3A. Fatal motor vehicle accidents in Michigan, as a rate per 1.000 .000 licensed driving population. Plotted by seven-day periods. 


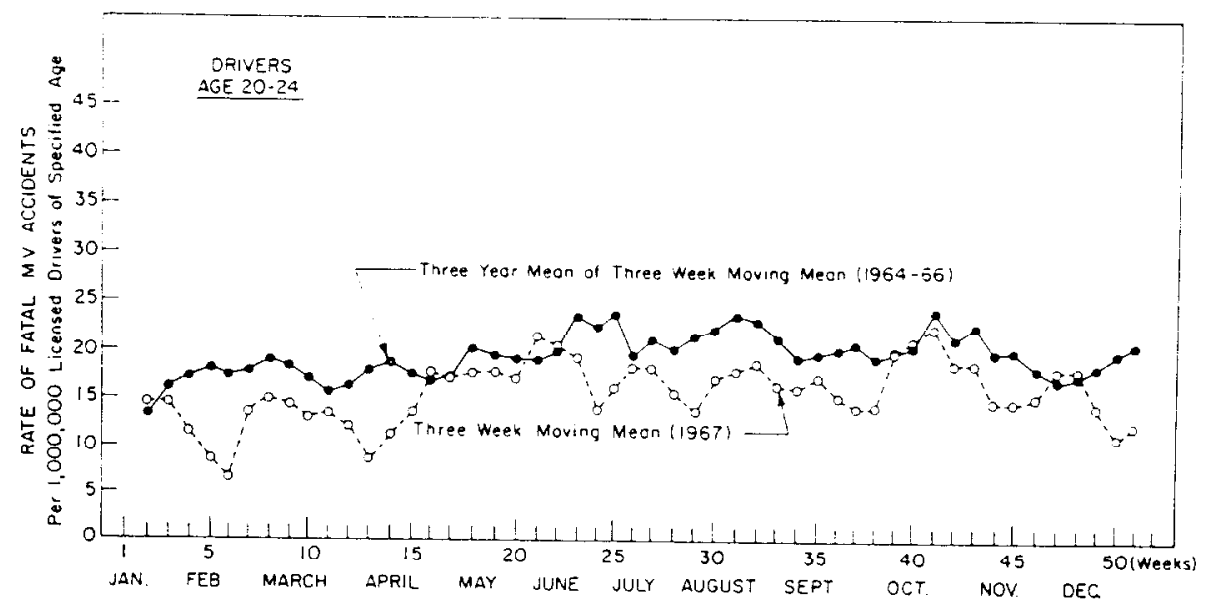

FIG. 3B. Fatal motor vehicle accidents in Michigan. as a rate per 1.000 .000 licensed driving population. Plotted by seven-day periods.

1967 was on the whole a good year with almost every one of the 7 day periods of the 3 week moving mean falling below expectancy. Only weeks 15-22,39-41 and 47-48 equalled the weekly rates for the preceding 3 years. Could $13 / 52$ weeks be lower simply by chance? This seems unlikely. Could the lower rates be due to a sharp rise in the denominator (the number of licensed drivers, age $20-24$ in 1967 is 627,152)? This also seems unlikely. In fact, a sizable number of such drivers were probably diverted from Michigan highways to overseas military service, with licenses still listed as active in Lansing. Could some safety measures, whatever their nature, be responsible so that perhaps the entire year was safer for most drivers in the state? This single graph cannot tell us definitely, but if the data were extended for 1968, one could compare the 1 year time span and derive some estimate of the performance of this age group.

In Fig. 3C. one notes that for drivers aged 18-19, in the year 1967 , their performance as

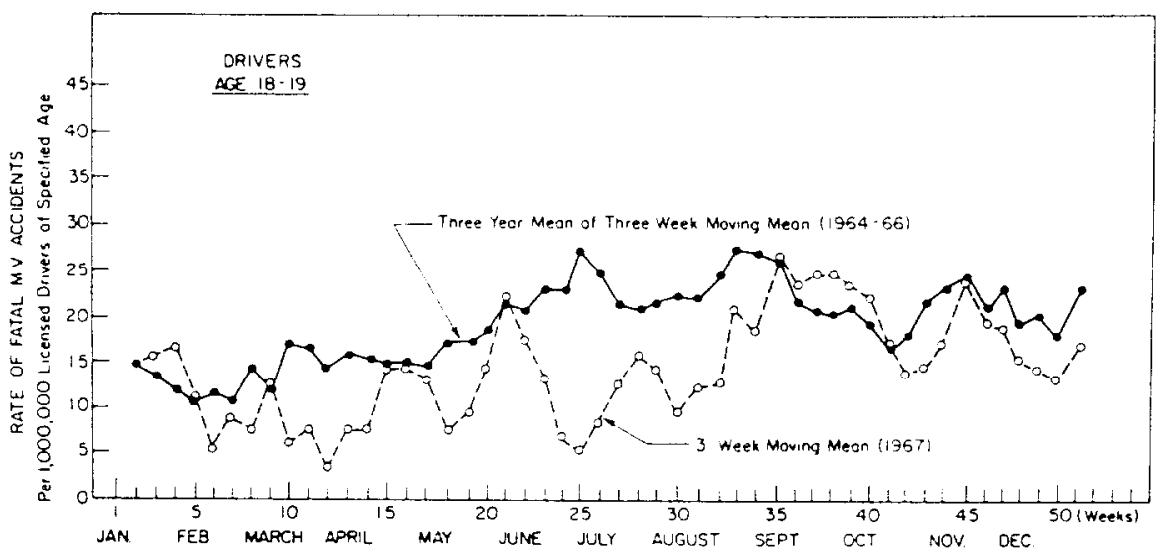

FIG. 3c. Fatal motor vehicle accidents in Michigan, as a rate per $1.000,000$ licensed driving population. Ploted by seven-day periods. 
a whole was below latal accident involvement of preceding years and relatively much better than for the slightly older 20-24 year old drivers! In certain periods, however, they were again at high risk. notably during the twenty-first week (around graduation) and then during weeks 35 through 40 . which may be related to going back to school and the involvement in social and athletic activities of the high school year. Whatever benefit occurred in 1967 for these drivers seems to be concentrated in the middle of the summer. Why did the driving improvement occur? One consideration in this single year comparison is the fact that 1967 was marked by civil disturbance with riots. or their threat, affecting most of the major cities in Michigan. What effect did the riots have on availability of police for traffic patrol and enforcement? What effect did the disorders have on miles driven during the summer" These facts are needed before one can speculate on how much of the violent or aggressive behavior was channeled into political or protest activities, rather than into motorized aggression. Further speculation is not warranted, but it is worth noting that such questions usually escape any kind of quantitative consideration unless the actual data are plotted in a time-series approach.

\section{Why time-series analysis in traffic salety"}

In considering the availability of rapid data processing. there is no real difficulty in programming these kinds of frequencies (number of drivers involved in FMVA by agespecific groups) into an ongoing time-series. For a relatively small input we can plot ongoing data for comparison with the expected moving mean or the expected frequencies. Such surveillance techniques require effective cooperation between the data processing, research, functional. and administrative units of police or highway safety departments. With the rapid growth of the traffic problem and advances in technology, the several parts of the team need more cooperation and teamwork than ever. The time-series approach provides an ongoing feedback mechanism that presents the information in an interesting and meaningful way, limited always by the restraints of the data. Experience in public health agencies indicates that similar data, even if imperfect in some details. can yield trends, short term effects, and aberrations. These episodes or trends stimulate one to initiate investigations of aberrations which may lead to either (a) detection of errors in reporting or in the data processing, or (b) to meaningful information about the causes of the fluctuations in the events. For example, the rising occurrence of fatal events as shown in the age group (18-19) in June, may present a real target for traffic efforts directed at the teenage driver; similar efforts directed in mid-February may be much less ellective. Evaluation of programs can be aided by comparing short and longer term trends. by geographic area, by age group and by program type (e.g. preventive or corrective). Time series can be developed not only for age-of-drivers-involved, but also for single car versus multiple car crashes, for types of roadway, for day-dusk-night patterns etc. Whether these analyses become burdensome or irrelevant depends, of course, on the needs, depth and interests of the department involved. At this stage in the study of highwaly salfety, simplicity would seem to be the theme of time-series applications to available traffic data.

\section{PART III. RELATED KINDS OF ANALYSIS}

The effects of season, estimated mileage and age

A nalyses of the data utilizing police records were also carried out in ways other than the time-series approach. These analyses could have been done independently of the time-series approach, but, in fact, they were developed to answer questions arising from the preceding 
time-series data concerning the effects of season, age of driver, and estimated miles driven. For example. Figs. $4 \mathrm{~A}$ and $4 \mathrm{~B}$ were developed to examine the performance of age groups involved in fatal motor vehicle accidents by the four major seasons in Michigan comparing the most recent year (1968) with the preceding year (1967).

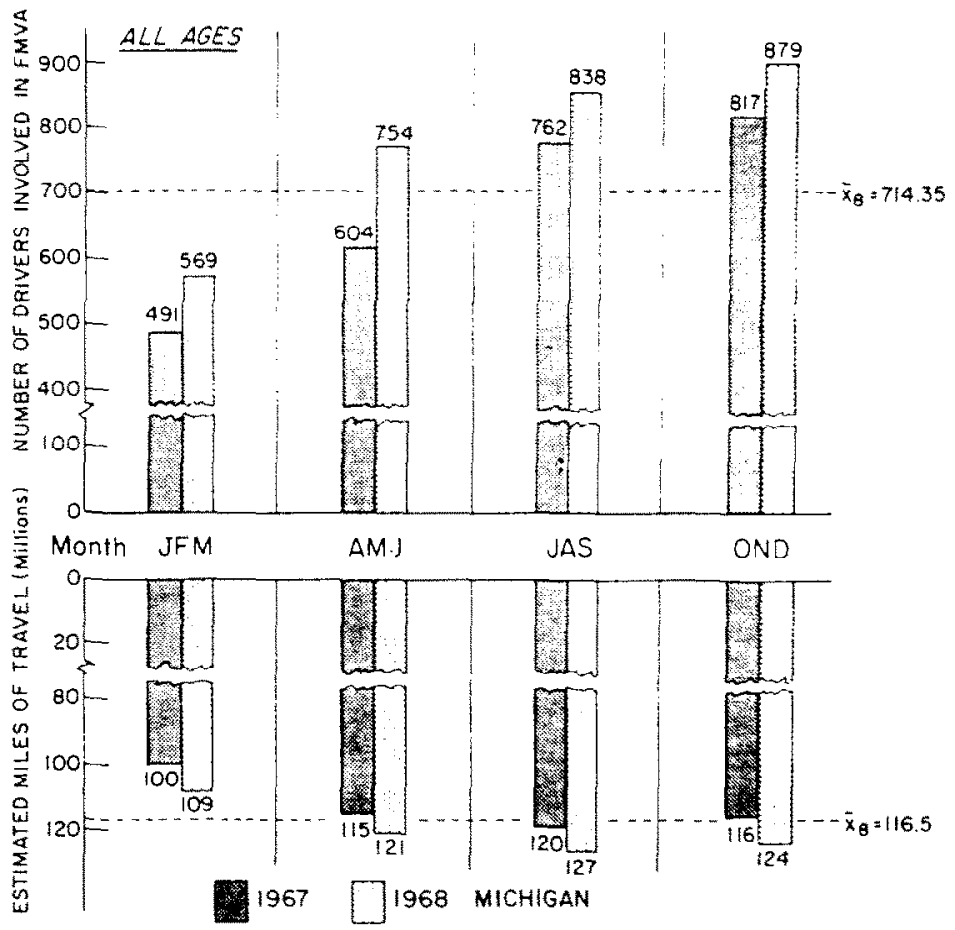

Fig. 4a. Seasonal distribution of falal motor vehicle accidents and estimated miles of travel, 1967-1968. Comparison by quarters of the year. in Michigan. all ages of drivers involved.

When the numbers of drivers involved in FMVA of all ages are plotted by season. one notes a steady rise from the low in the winter (JFM) regardless of year to the highest period in the autumn (OND) (see Fig. 4A). An eight period mean value, $\pi_{8}$, covering 2 years of 4 quarters each, is shown to help in the visual comparisons. The FMVA approximately correlate with the estimated miles of travel on the lower portion of this graph which also tends to have an increasing curve.

Is the age of drwer involved an important variable in regard to season of the year"? In Fig. 4B, one may detect age group differences by season and year. Comparison between age groups is noted by examining the graph vertically. For example, notice that the drivers aged 65 and over had very little change from 1967-1968;45-64 year old drivers had some increase as did those ages 25-44:20-24 year old drivers increased about 20 per cent (mostly in JAS) while the age group of 19 and younger increased their involvement in FMVA in 1968 compared to 1967 by about 40 per cent. This is largely attributable to their performance in the period. April, May and June of 1968, during which less than 10 per cent of the drivers (less than age 19) affected the overall pattern for the state. One can say that single year changes are not too reliable and these effects may oscillate from year to year. 


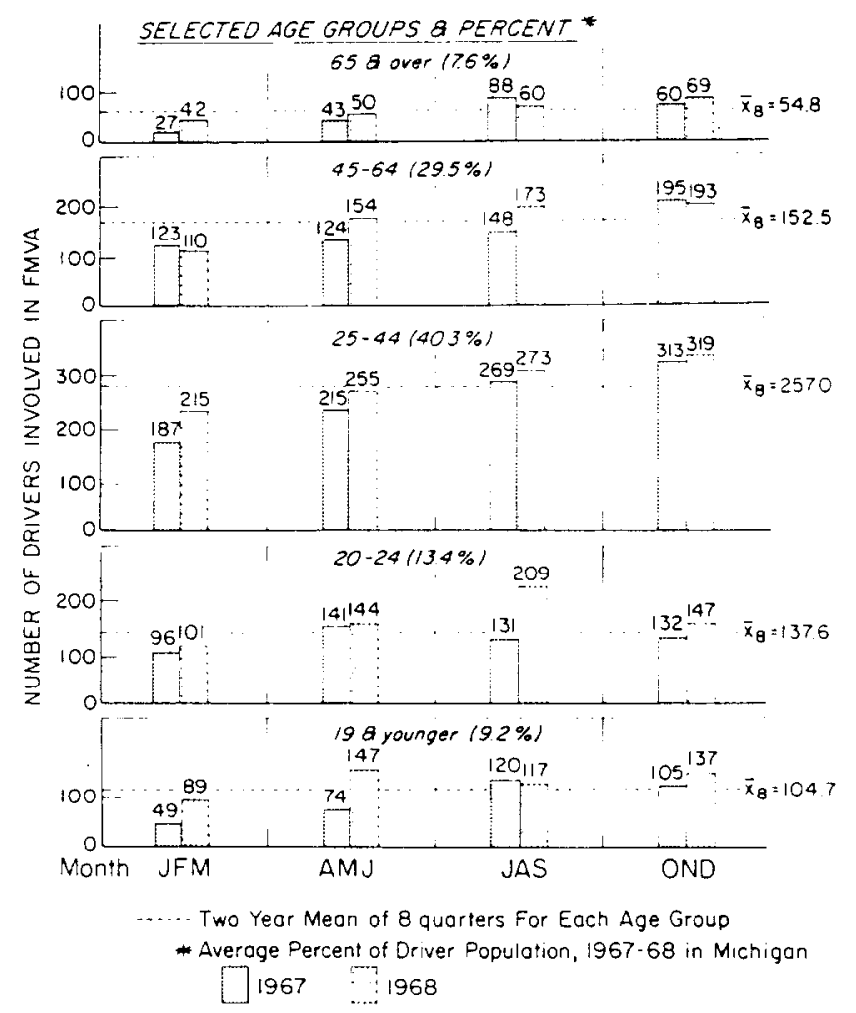

Fic; th. Seasonal distribution of lital motor vehicle accidents by age group of drivers involved. 1967-1968. Comparison by quarters of the year, in Michigan.

Nevertheless, if we do not examine these changes from year to year with some attention to high-risk groups, times and situations, our surveillance will be ineffective or too late to be of any value.

\section{How did loung drivers perform in 1968?}

The surveillance of the young driver in fatal accidents was maintained during 1968 by tabulating the ongoing data as shown in the cells in Table 2A, which compares 1967 by season with 1968, as well as listing the proportions of licensed drivers at risk for each age group. By midyear of 1968, it was clear the numbers were increasing: $569+754$ drivers versus $491-604$ drivers involved in 1967. The net change and proportions of change are tabulated in Table 2B. Note that of the year long net increase of 336 drivers involved, almost half of the increase $(+150)$ occurred in April-May-June. A vertical scan of the spring period indicates the over-involvement of the teenaged drivers: 73/153 of the ageknown-drivers being 19 or younger. In the summer period (July-August-September), the performance of the 20-24 year old drivers was equally striking.

How did young drivers perform in 1968, when rates are calculated?

The rates in Table $2 \mathrm{C}$ were derived from the basic data in $2 \mathrm{~A}$ and for simplicity, the seasonal columns were totalled as annual rates; the amount and proportions of change are tabulated. The denominators of the rates represent the best available licensure data in the state. 


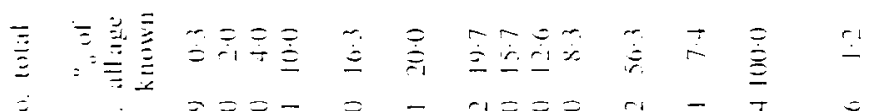

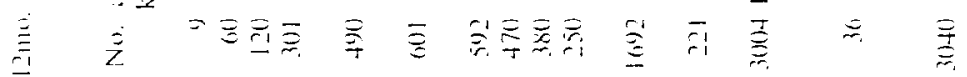

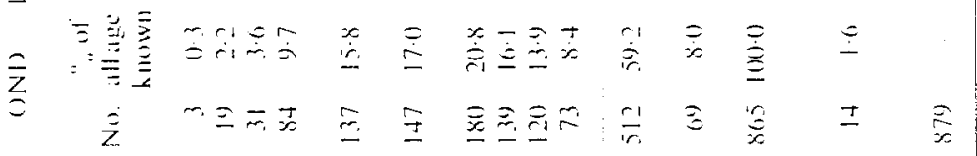

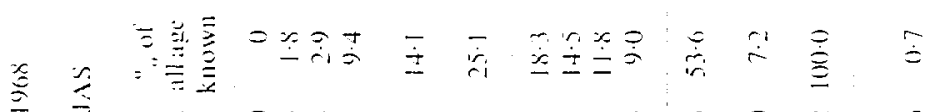

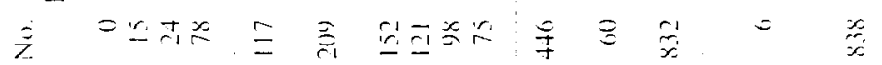

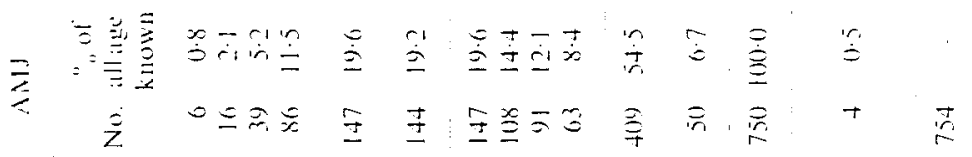

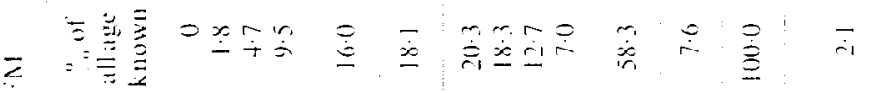

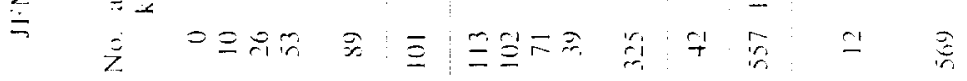

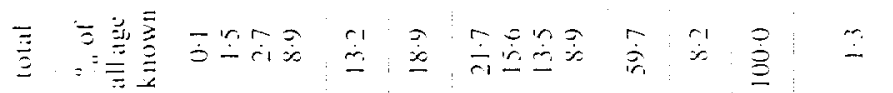

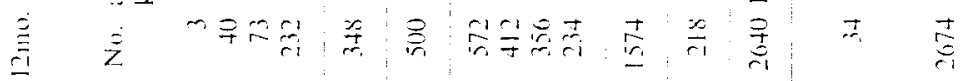

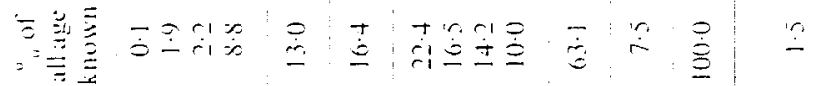

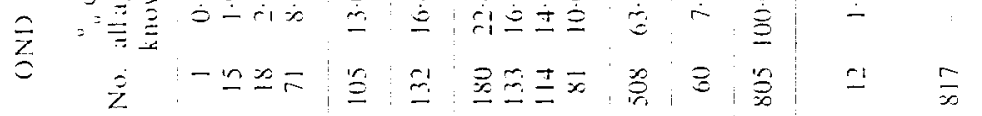

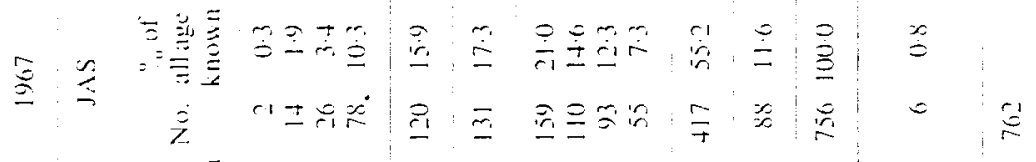

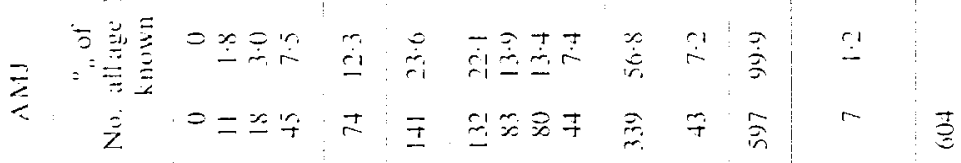

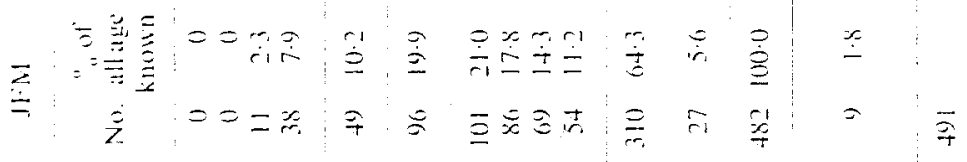

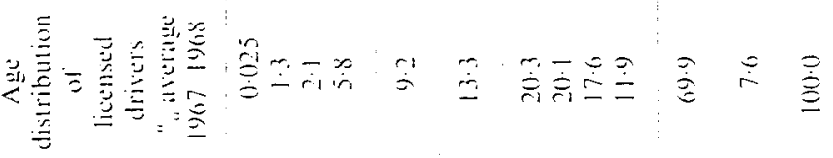




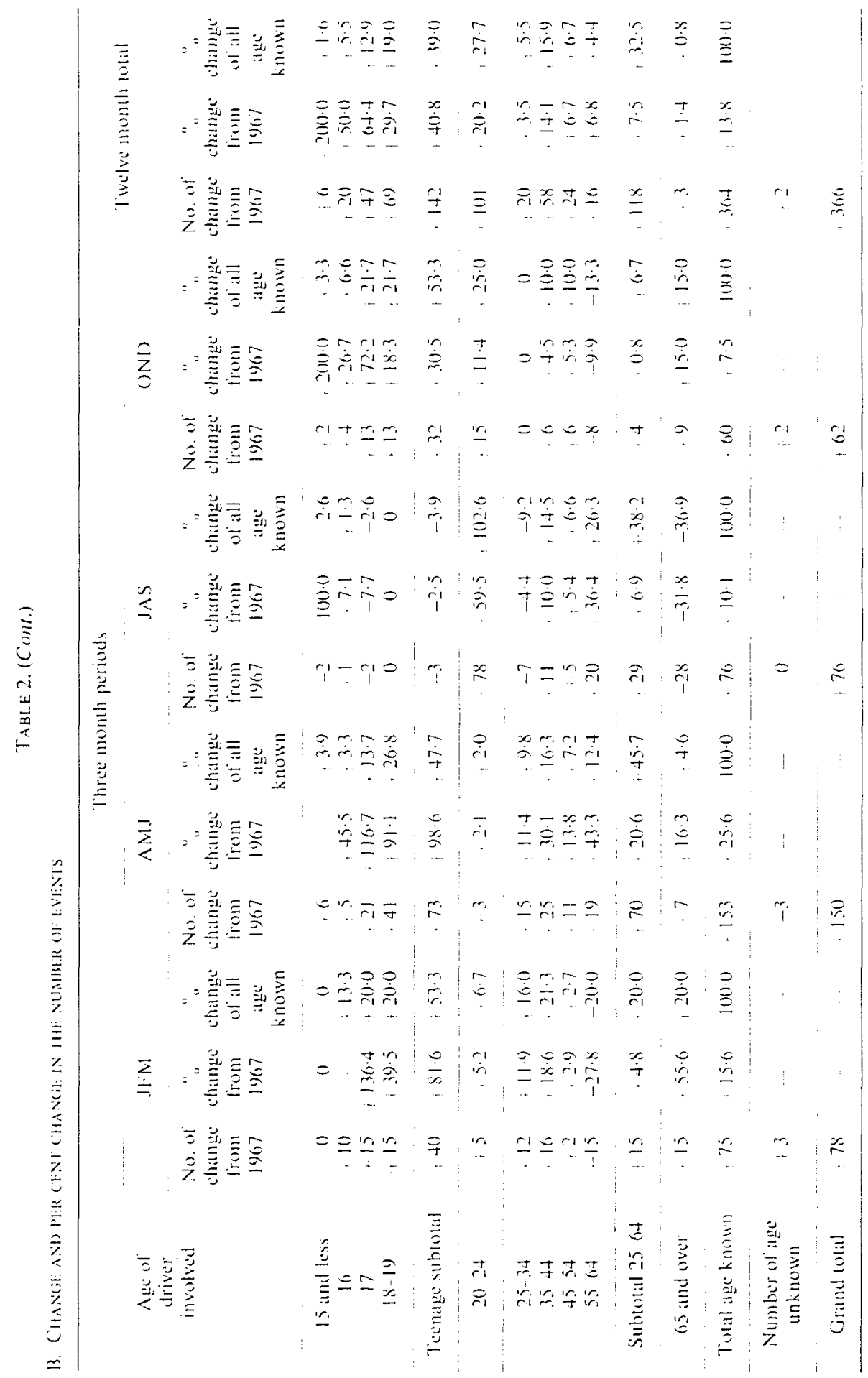


TABLE 2.(COMII.)

C. ANNLAI RATES (PER 10.000 LICESED DRIVERS IX THE SPFCIFIED AGE GROCP)

\begin{tabular}{|c|c|c|c|c|}
\hline $\begin{array}{l}\text { Age of } \\
\text { Ariver } \\
\text { involived }\end{array}$ & $\begin{array}{c}1967 \% \\
\text { Rate of FWVA } \\
\text { per } 10.000 \\
\text { I month wotal }\end{array}$ & $\begin{array}{c}1968_{+}^{+} \\
\text {Rate of FMVA } \\
\text { per } 10.000 \\
12 \text { month total }\end{array}$ & $\begin{array}{c}\text { Change } \\
\text { rate of Filla } \\
\text { per } 10,00 \text { ) } \\
12 \text { monch tocal }\end{array}$ & $\begin{array}{c}\text { Per cent } \\
\text { rate change } \\
\text { from } 1967 \\
12 \text { month toul }\end{array}$ \\
\hline 15 and less* & $\ldots$ & -.- & & \\
\hline 16 & $4 \cdot 7$ & 131 & $-3 \cdot 4$ & $.178 \cdot 7$ \\
\hline 17 & $6 \cdot 3$ & 114 & 51 & $-80 \cdot 9$ \\
\hline $18-19$ & $7 \cdot 7$ & 120 & -43 & .558 \\
\hline Teeniage subtotal & 6.9 & 122 & -53 & .76 .8 \\
\hline $20-24$ & 8.0 & 92 & -12 & -150 \\
\hline $25-34$ & 6.7 & 55 & $-1 \cdot 2$ & $-17 \cdot 9$ \\
\hline $35-+4$ & 4.5 & $+s$ & .0 .3 & $.6 \cdot 6$ \\
\hline $45-54$ & 4.4 & 45 & $\cdot 0 \cdot 1$ & $\cdot 2 \cdot 2$ \\
\hline $55-6 t$ & $4 \cdot 2$ & 42 & 0 & $0^{-}$ \\
\hline Subtotal 25-64 & 5.7 & $+\bar{x}$ & -0.2 & $-4 \cdot 0$ \\
\hline 65 and over & 7.7 & 46 & $-3 \cdot 1$ & $-40 \cdot 2$ \\
\hline Total age unknown & 58 & 60 & .02 & $-3 \cdot 4$ \\
\hline
\end{tabular}

"Vumbers loo small to calculate rates.

++ Denominators tor number of licensed drivers trom U.S. Dept of Transportation. Bureau of Public Roads. Washington D.C. 20591. Table DL-21, 1967 and Michigan Dept. of State. Lansing. Michigan 48918. Chart 12 , 1968. respectively.

These data as rates (see Fig. 5) show that the youngest drivers were over-represented in 1968 in FMVA compared to 1967. One might argue that their performance in 1967 with a rate of $6.9 / 10.000$ licensed drivers was unusually good, but the margin of increase makes such an interpretation most unlikely. The other impressive change was in the 65 year and older age group, which seemed to show a substantial improvement for the year (7.7 compared to $4 \cdot 6 / 10,000$ licensed drivers).

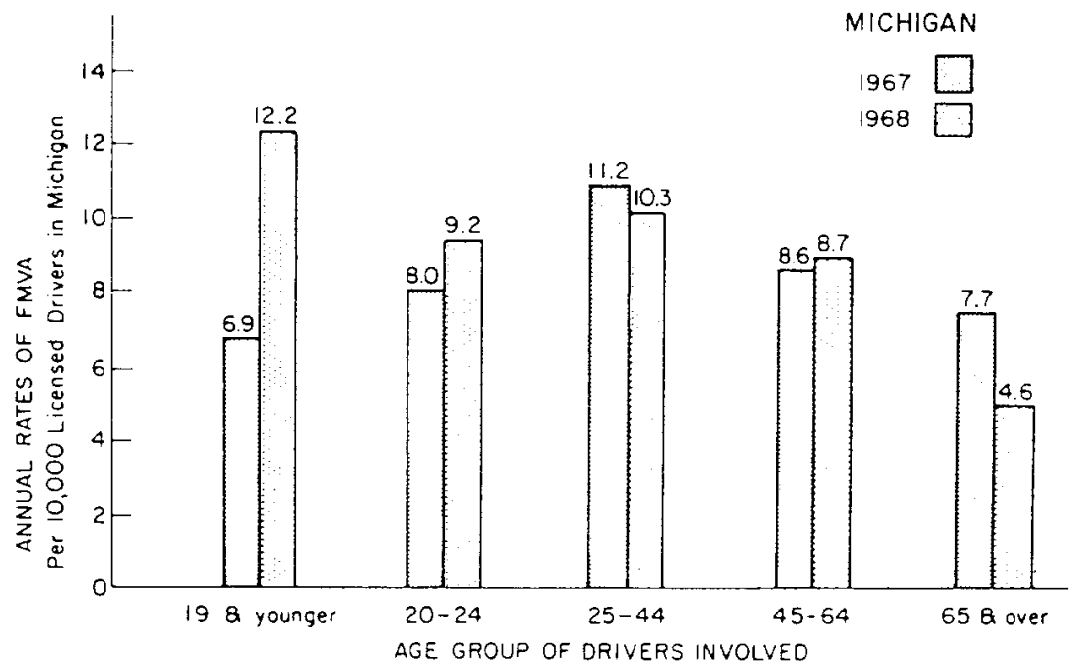

Fici. 5. Annual rates of latal motor vehicle accidents per 10,000 licensed drivers in Wichigan. $1967-1968$, by age group of drivers involved. 
Dolypes of fatal motor vehicle accidents add to our understanding of the voung driver prohlem."

A standard feature of accident reporting indicated in the basic police document (Figs. 1 A $.1 B$ ) is the type of collision, the number and direction of cars involved. The details and evidence as to precise accident causation are missing from routine reports, requiring data provided by trained, equipped. multidisciplinary teams. Can the simple, routinely available features of the young driver in FMVA suggest to us ways in which the problem should be analyzed? For example, it has been shown (Penn, 1963-1965) that the younger the driver the more likely will be his involvement in a certain type of fatal accident, namely, single car accidents. These data for Michigan for the years 1960-1966 have been plotted. The use of age of person killed as the indicator of problem driving is not fully satisfying. but it is felt that age of driver is the factor of most concern, not the age of person deceased. For example, the younger driver has a greater ability to survive near-fatal accidents than do older persons who do not have the stamina to recover from multiple fractures, chest injuries. head injuries etc. On the other hand, it is unlikely that the essential shape of the curve for deceased shown in Fig. 6 would be much different using age of driver involved.

Examining the available data by age of person killed, note that for a 6 -year period, the number ol deaths involving single car accidents (on the left-hand margin of the graph) was highest for the 5-year age group 20-24. These deaths were closely followed by the age group 15-19.

Then there is a decline for the group 25-29, indicating that drivers statistically cross a 'barrier' at about 25 years of age (which has been a useful dividing line on an empirical basis for insurance raltes). What happens between age groupings $20-24$ and $25-29$ for this young population that so sharply affects their behavior behind the wheel and their performance in mortality statistics? The subsequent decrease in the number of deaths involving single car accidents is steady for age groups in the thirties and the forties, reaching

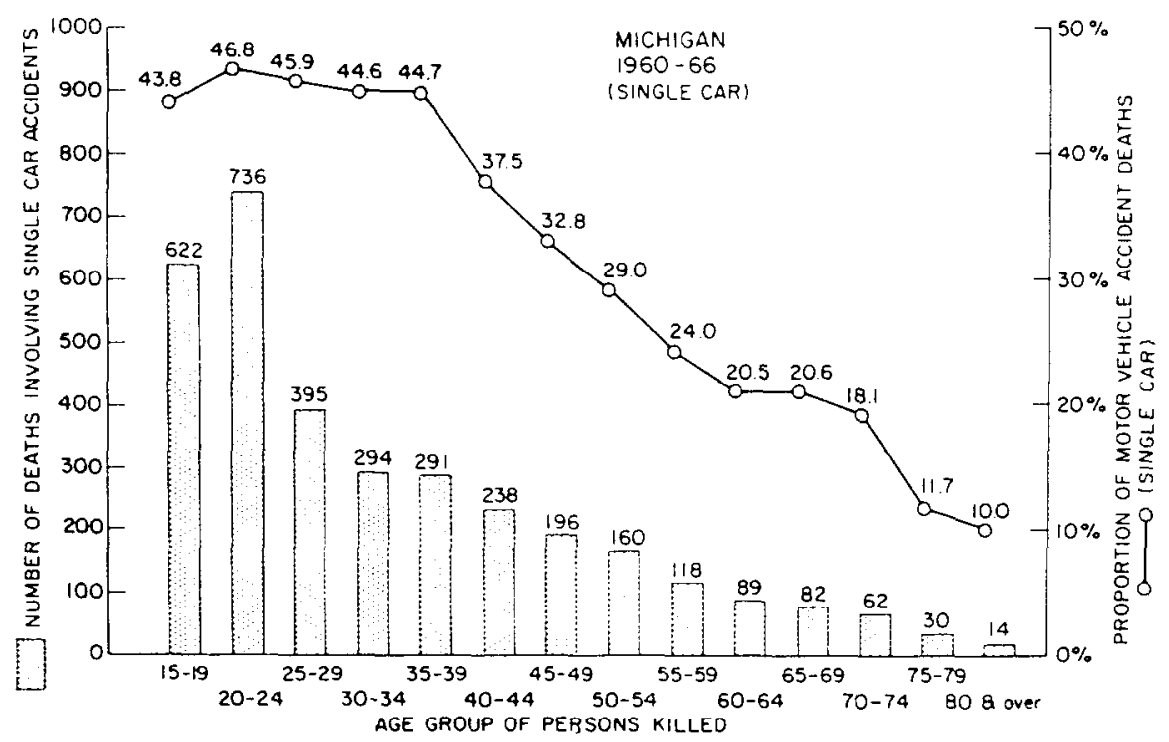

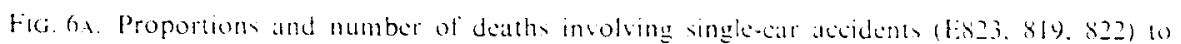
total motor vehicle accident deaths (E810 to 825 excluding E812, 825 . 824) in Michigan 1960-1966 by age groups of persons killed. 
minimal numbers in the most senior citizens. These figures, of course, are related to driving exposure, which cannot be minimized. When such data become available, the denominators can take into account number of miles driven. In the meantime. these numbers do indicate how and to whom the deaths are occurring. Our job in prevention should be to recognize the deaths where they are most prominent, and where driver-error seems to play an important role.

In the second part of Fig. $6 A$, the continuous line presents the same data derived as a proportion of motor vehicle accidents. which are single car of the total motor vehicle accidents for each age group. The denominators for these calculations have excluded pedestrian deaths. bicycle deaths, or other vehicle deaths, concentrating on those which involve drivers*, the numerators emphasize single car errors (such as running off the roadway, hitting fixed objects, overturning, etc.) as distinct from the multiple car crashes. The percentages are essentially the same for age groups 15-39. averaging 44.45 per cent

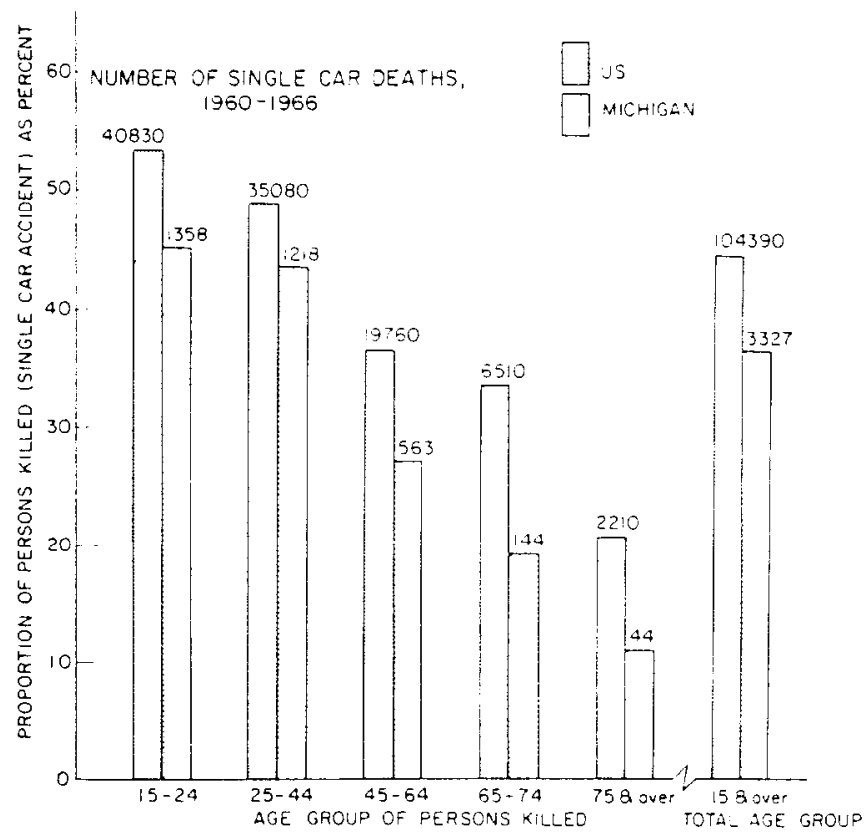

Fic; 61. Proportions and number of deaths involving single car accidents by age group of persons killed in U.S. $1960-1966$ and Michigan 1960-1966.

single car accidents. These percentages drop quite sharply after age 40 . There is a flattening of the trend in the 60-74 age groups. If there is anything that can be learned about single car crashes which would help reduce the toll of persons killed, this knowledge should be

* Proportion of F.MVA (single car) used in Fig. 6A =:

E819. E821, E822. E823

E810 to E823, excluding E812 (Total Accidents, excluding pedestrians. Vion-Traffic deaths)

E\$10 to E\$25 refer to the classification of deaths used in the Mamual of the Intermational Live of Cames of Death. Vll Revision (1955), Vol. 1. WHO. Cieneva. 
directed most effectively at the youngest age groups. Nowhere is it more important to stress the effects of excessive speed, loss of control of the vehicle. errors in judging conditions, use or non-use of seat belts than in the youngest age groups. In what other age group of drivers can one say so consistently that it is not really "the other driver"? Year after year. in almost half of the young driver fatal crashes, it is the single car operator who has become the victin of errors in the nan-machine-roadway combination. Such solo errors may be the result of over-confidence. inexperience. or detects in car design. roadway design and traffic patterns. Whatever the combination or permutation of factors they can result in a fatal crash.

\section{How does . Wichigan compare with the U.S. in single car crashe's?}

In Fig. 6в. single car deaths are plotted by age group of persons killed for Michigan and the U.S. We see the same shaped curve for the U.S. as a whole as for Michigan, although the drop-ofl in Michigitn is more dramatic for persons in the middle age group than it is in the U.S. as a whole. This close resemblance of single car, off-the-road type of crashes in Michigan and the U.S. as the proportions of the rest of the U.S. underscores the fact that the exposure factors are important. but inexperience is especially important in the 15-24 year old group.

\section{SUMMARY}

Can epidemiologic surveillance techniques be applied to routine police data collection.'

Data are presented from Michigan police files (supplemented in part by vital statistics) which indicate the pivotal role of the youngest drivers, aged 19 years and younger (who constitute less than 12 per cent of the licensed driving population) in the fatal motor vehicle accident record of the entire state.

In the recent year. 1968, in a short 3 month spring period, these teenaged drivers doubled their FMVA involvement from 74 to 147 , and their rate increased from 6.9 to $12 \cdot 2 / 10,000$ licensed drivers.

Other age groups involved as drivers in fatal motor vehicle accidents are also studied, as well as types of accidents (single-car versus multiple-car crashes).

The epidemiologic techniques employed with available police data may be summarized as follows:

(a) Choice of index of measure, number of FMVA by age of driver involved as best characterizing the driving aspect of the traffic problem to be studied.

(b) Development of expected frequencies (3 or 5 year means) of recent experience for comparison with current experience.

(c) Use of rates wherever possible to relate numerators (numbers of drivers involved in fatal MVA) to denominators (numbers of licensed drivers); attention to the shortcomings and limitations of the data at each stage of interpretation.

(d) Use of time-series plotting of data to preserve detail as 7-day periods while smoothing the curves by 3 week moving means. This permits estimation of a tolerance zone, and facilitates the detection of short term or long term aberrations.

(e) Use of descriptive classification of accidents (single-car versus multiple-car) as one measure of age effects. geographic comparison, and trends.

(f) Emphasis on surveillance or monitoring the best available data in an ongoing way to provide current information in sufficient detail to alert responsible agencies to the 


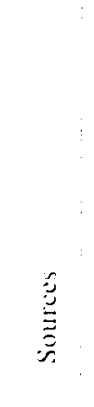

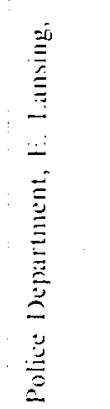

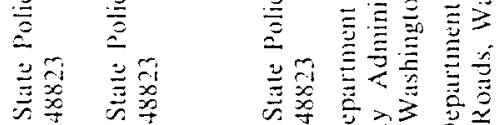

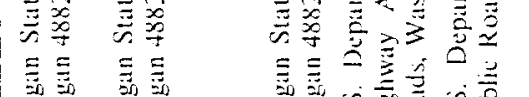

(1)

:

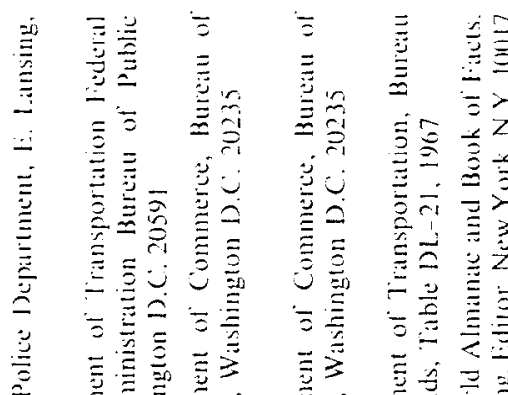

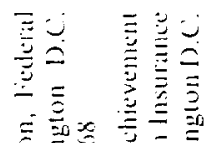

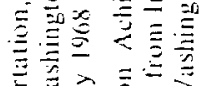

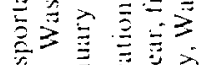

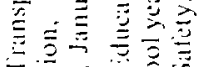

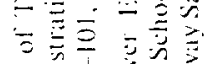

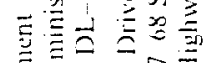

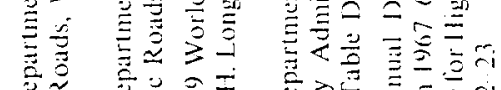

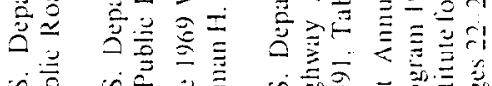

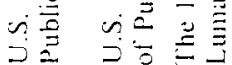

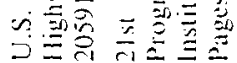

$=$

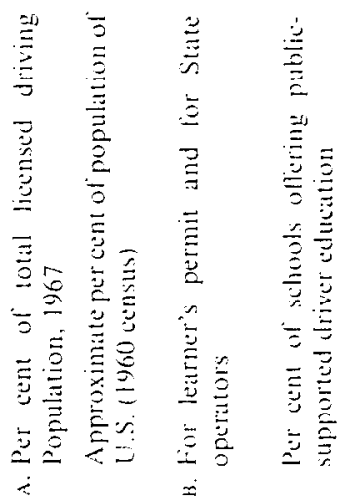
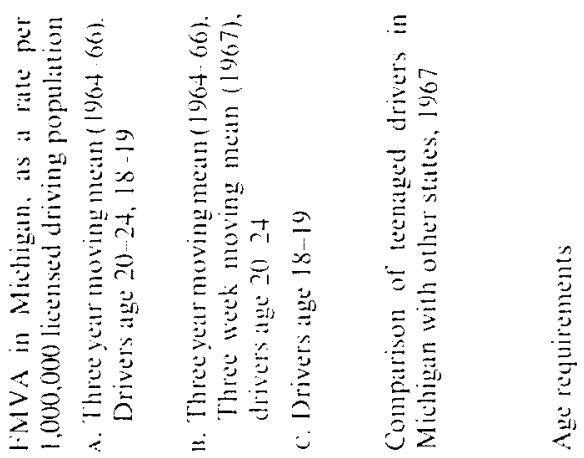

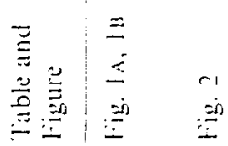
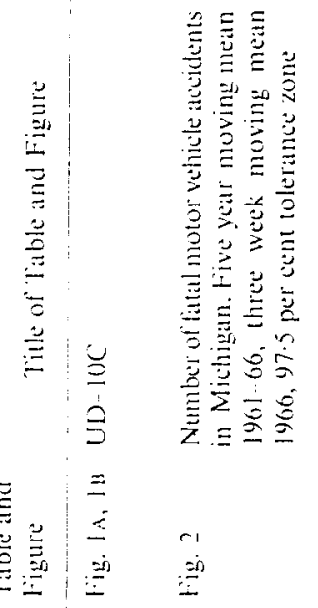

$\stackrel{m}{=0}$

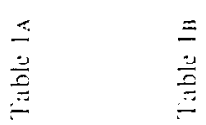




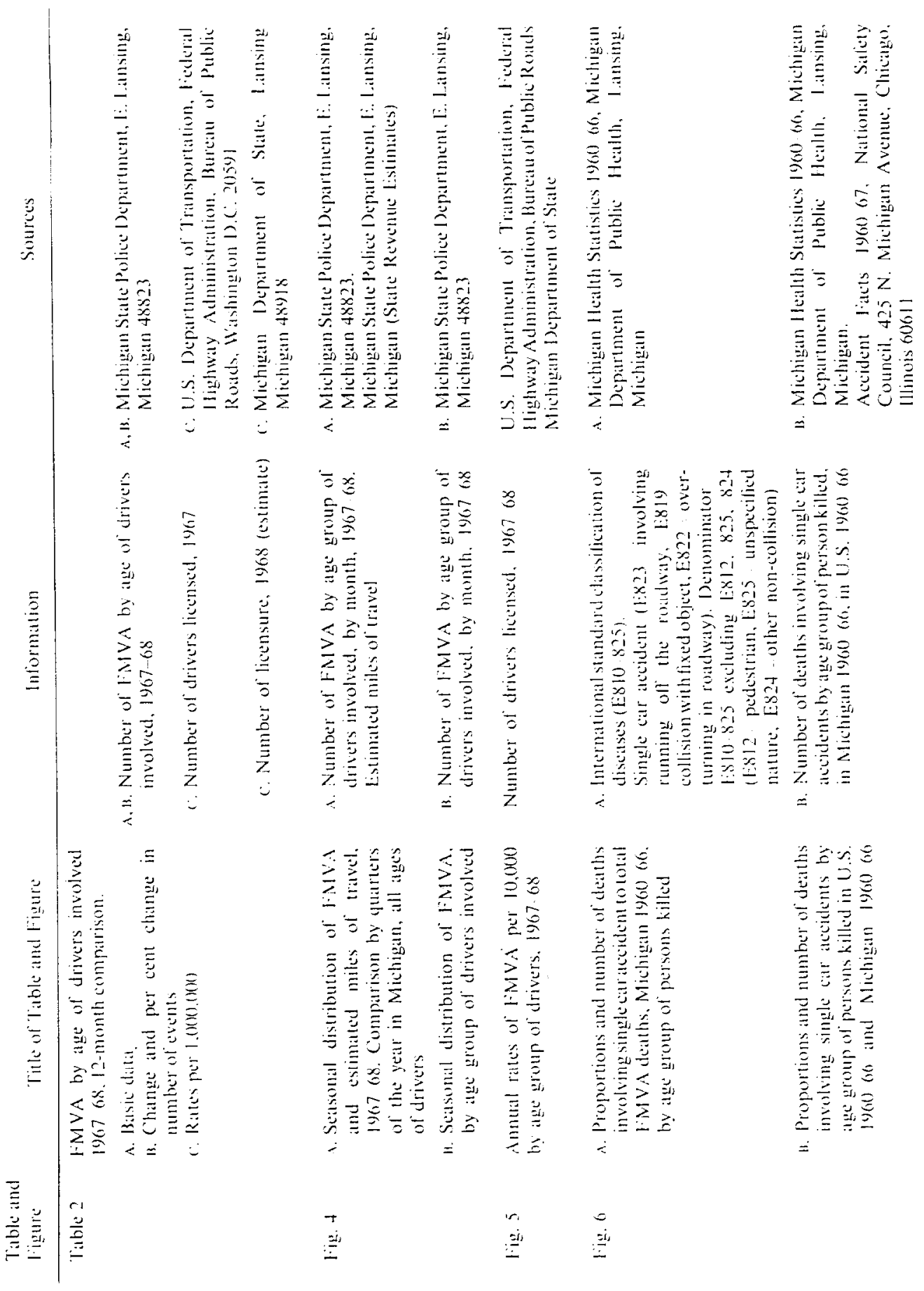


quality and magnitude of the problems. This approach requires selection of the most meaningful indices and frequencies for ongoing evaluation.

(g) Intelligent wse and interpretation of traffic reports must keep up with the technological advances in processing and storage of the growing volumes of information which now permit greater Hexibility and imagination than ever before anticipated.

\section{REFERE:YCES}

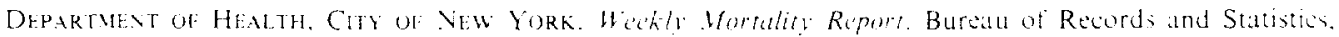
1 Ij Worth Street. New York. N.Y. 10013.

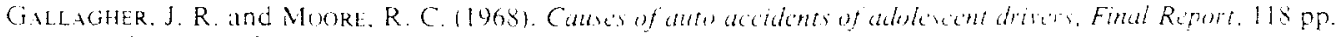
Harvard School of Public Heulth. Boston. Mass.

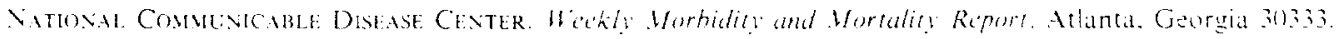
Also spectal disealse surveillance reports on intluenza, malaria. rubella. salmonellosi hepatiti :

Prez, D. C. and SCHLwax, S. H. (1969). Young drivers: road behavior and motivations. Third Tratic tecident Congres, May 29-June 1, 1969 . Vew York City N.Y. International Association for Accident and Tratio Medicine. (In press.)

PEN. H. S. (1963-1965). Causes and characteristics of single car accidents. Parts 1 IV. Depaltment of Californiat Highway Patrol. Sacramento. Calitornia.

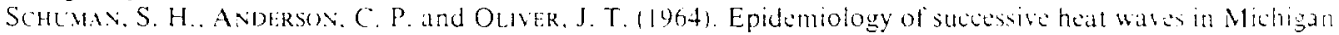
in 1962 and 1963.J. Am. med. As. 189, 733-738.

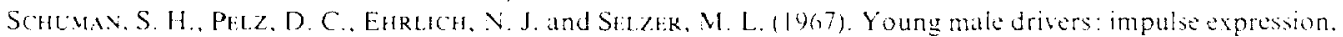
accidents, and violations. J. Am. med. Ais. 200, $1026 \cdots 1030$.

St:RFlivg, R. E. (1963). Wethods for current statistical analysis of exeess pneumonia-intuenza deaths. Puhl Hlih Rop. Wash 78, 494506. 